\section{Early intensive treatment normalises excess mortality in ACPA-negative RA but not in ACPA- positive RA}

With great interest, we read the recently published report by Poppelaars et al in which no excess mortality was observed in 155 patients with rheumatoid arthritis (RA) from the COmbinatie therapie $\mathrm{Bij}$ Rheumatoide Artritis (COBRA)-trial, who received early intensive treatment, compared with the general population (Standardised mortality rate (SMR) 0.80 (0.591.06)). ${ }^{1}$ The question whether mortality in RA has normalised is debated, as contradicting results have been published. ${ }^{2-8}$ In many of the studies on mortality, two important factors are not sufficiently taken into account: follow-up duration and disease subtypes. This might explain the conflicting results. Because thus far none of the reported studies incorporated both factors in the analyses, it is too soon to conclude that mortality is 'normal' again, as we will show here.

We compliment the authors on emphasising the importance of a long follow-up duration by showing in their meta-analysis that excess mortality in RA becomes fully apparent after $>10$ years. This implies that previous studies that reported on normalisation of mortality had insufficient follow-up to reach this conclusion. $^{2-5}$ Some studies with a short follow-up duration even showed a seemingly decreased mortality in RA, which may be due to a healthy inclusion bias. ${ }^{3-5}$

RA consists of two subtypes that are characterised by the presence or absence of RA-related autoantibodies, of which the presence of anti-citrullinated protein antibodies (ACPA) is most specific for RA. Both subtypes have known differences in the severity of the disease course. The study of Poppelaars et al did not stratify for ACPA, which is due to a small sample size $(n=155)$, leaving the question unanswered if mortality has normalised in both subsets of RA.

To assess the true impact of early intensive treatment on mortality, we performed a large study with up to 25 years of follow-up and sufficient power to stratify for ACPA. One thousand two hundred and eighty-eight patients with RA fulfilling the 1987 criteria, who were consecutively included in the Leiden Early Arthritis Clinic, were studied. According to treatment in
Table 1 Baseline characteristics of patients with RA treated without and with early intensive treatment

\begin{tabular}{|c|c|c|}
\hline & $\begin{array}{l}\text { No early intensive } \\
\text { treatment }\end{array}$ & Early intensive treatment \\
\hline & $(n=353)$ & $(n=945)$ \\
\hline Inclusion period & $1993-2000$ & 2001-2016 \\
\hline Women, n (\%) & $238(67)$ & $620(66)$ \\
\hline Age in years, mean (SD) & $56(16)$ & $58(15)$ \\
\hline $\begin{array}{l}\text { Symptom duration, days } \\
\text { median (IQR) }\end{array}$ & $136(75-279)$ & $117(58-234)$ \\
\hline Current smoker, n (\%) & $98(30)$ & $211(25)$ \\
\hline ESR, median (IQR) & $37(21-58)$ & $29(14-45)$ \\
\hline 66-SJC, median (IQR) & $10(5-16)$ & $6(3-11)$ \\
\hline RF-positive, n (\%) & $193(55)$ & $543(59)$ \\
\hline ACPA-positive, $n(\%)$ & $199(56)$ & $456(51)$ \\
\hline
\end{tabular}

ACPA, anti-citrullinated peptide antibody; ESR, erythrocyte sedimentation rate; $\mathrm{RF}_{\text {, }}$ rheumatoid factor; SJC, swollen joint count.

routine care, patients included between 1993 and 2000 received initial treatment with only non-steroidal anti-inflammatory drugs or mild disease-modifying antirheumatic drugs (eg, penicillamine, gold, hydroxychloroquine). Patients included between 2001 and 2016 were treated with early intensive treatment with methotrexate as first-line treatment. Treat-to-target became routine during this period as well. Mortality data were obtained from the civic registries on 1 June 2018. Mortality was compared with the general population in the Netherlands with SMRs adjusted for birth year, gender and calendar year. SMRs were determined for both treatment strategies, after stratification for follow-up duration ( $0-5$ years, $5-10$ years, $>10$ years) and disease subset (ACPA status).

Baseline characteristics are shown in table 1. Two hundred and forty-eight patients died during follow-up. SMRs increased during follow-up and excess mortality became evident after 10 years of disease $(0-5$ years SMR 0.55 (0.41-0.73); 5-10 years $1.08(0.87-1.33)$ and $>10$ years $1.39(1.15-1.66)$; figure $1 \mathrm{~A})$. Stratification for disease subset revealed that a decreased mortality was observed within ACPA-negative RA (SMR 0.80 $(0.67-0.96))$ and an increased mortality within ACPA-positivity
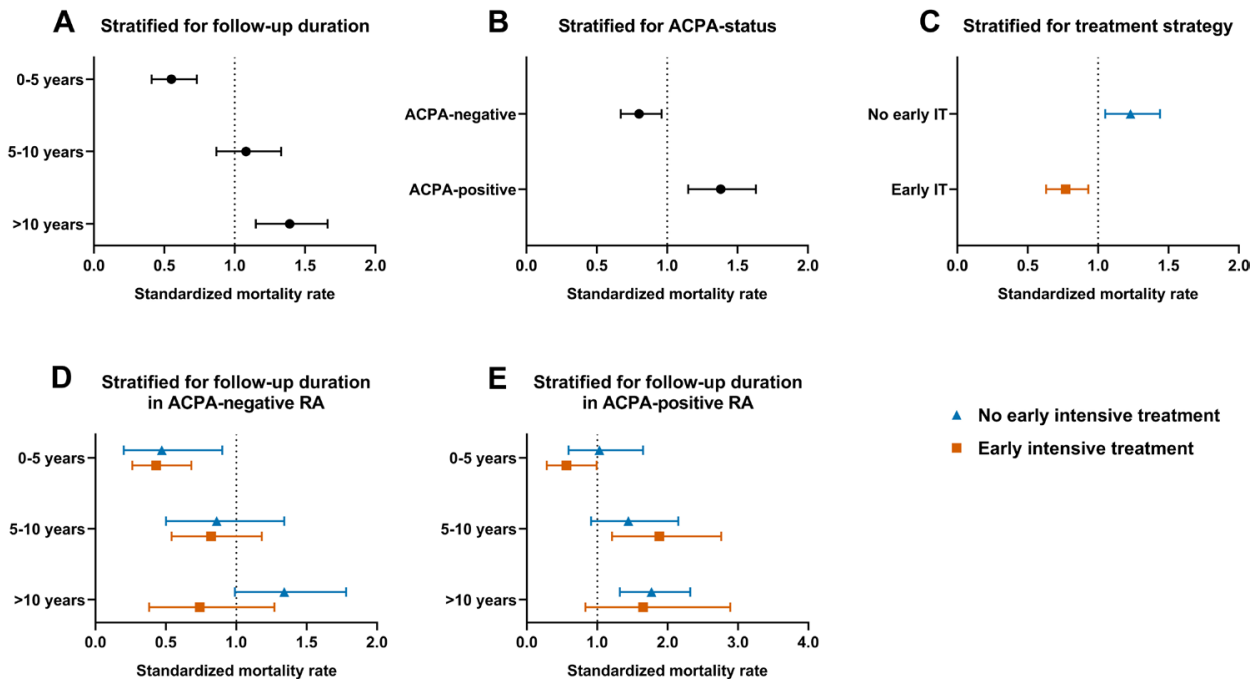

- Early intensive treatment

Figure 1 Mortality of patients with rheumatoid arthritis (RA) compared with the general population, stratified for follow-up duration (A), disease subset characterised by anticitrullinated protein antibody (ACPA) status (B), early intensive treatment (IT) (C) and these variables combined (D and E), showing that excess mortality has normalised by early intensive treatment in ACPA-negative RA but not in ACPA-positive RA. 
RA (SMR 1.38 (1.15-1.63); figure 1B). Comparing the two treatment strategies without considering follow-up duration and ACPA status revealed that early intensive treatment was associated with a decrease in mortality compared with the general population (SMR 0.77 (0.63-0.93)), in contrast to group without early intensive treatment (SMR 1.23 (1.05-1.44); figure 1C). This is concordance with the findings from Poppelaars et al. Subsequent stratification for follow-up duration and ACPA-status showed that excess mortality became apparent after 10 years of disease in ACPA-negative RA without early intensive treatment and that early intensive treatment had normalised this excess mortality. In ACPA-positive RA, in contrast, excess mortality emerged after 5 years of follow-up and was not influenced by early intensive treatment.

In conclusion, sufficient follow-up duration and stratification for relevant disease subsets are important to disentangle the effects of treatment on mortality. Our data from a large cohort of patients with RA with up to 25 years follow-up showed that excess mortality has resolved since the introduction of early intensive treatment in ACPA-negative RA, but excess mortality remains an issue in ACPA-positive RA. This underlines that RA consists of two types with differences in treatment response and long-term outcome and that additional efforts are still needed to reduce the increased risk of early death in ACPA-positive RA.

\section{Xanthe ME Matthijssen $\odot,{ }^{1}$ Tom WJ Huizinga, ${ }^{1}$ Ellis Niemantsverdriet, ${ }^{1}$ Annette HM van der Helm-van Mil ${ }^{1,2}$ \\ ${ }^{1}$ Rheumatology, Leiden University Medical Center, Leiden, The Netherlands ${ }^{2}$ Rheumatology, Erasmus Medical Center, Rotterdam, The Netherlands}

Correspondence to Xanthe ME Matthiissen, Rheumatology, Leiden University Medical Center, Leiden 2300 RC, The Netherlands; X.M.E.Matthijssen@lumc.nl

Contributors XMEM and AHMvdH-vM contributed to the conception and study design. XMEM analysed the data. XMEM, TWJH, EN and AHMvdH-vM contributed to interpretation of the data. XMEM and EN contributed to acquisition of the data. XMEM and AHMvdH-vM wrote the first version of the manuscript and TWJH revised it critically. All authors read and approved the final version of the document.

Funding The research leading to these results has received funding from the Dutch Arthritis Foundation and the European Research Council (ERC) under the European Union's Horizon 2020 research and innovation programme (Starting grant, agreement No 714312).

Competing interests None declared.

Patient consent for publication Not required.
Ethics approval 'Commissie Medische Ethiek' of the Leiden University Medical Centre (B19.008).

Provenance and peer review Not commissioned; internally peer reviewed. Data availability statement Data are available upon reasonable request. (C) Author(s) (or their employer(s)) 2020. No commercial re-use. See rights and permissions. Published by BMJ.

\section{Check for updates}

To cite Matthijssen XME, Huizinga TWJ, Niemantsverdriet E, et al. Ann Rheum Dis 2020;79:e124.

Received 5 June 2019

Accepted 8 June 2019

Published Online First 22 June 2019

\section{SLinked}

http://dx.doi.org/10.1136/annrheumdis-2019-215863

Ann Rheum Dis 2020;79:e124. doi:10.1136/annrheumdis-2019-215843

ORCID iD

Xanthe ME Matthijssen http://orcid.org/0000-0001-7332-8072

\section{REFERENCES}

1 Poppelaars PB, van Tuyl LHD, Boers M. Normal mortality of the cobra early rheumatoid arthritis trial cohort after 23 years of follow-up. Ann Rheum Dis 2019;78:586-9.

2 Markusse IM, Akdemir G, Dirven L, et al. Long-term outcomes of patients with recentonset rheumatoid arthritis after 10 years of tight controlled treatment: a randomized trial. Ann Intern Med 2016;164:523-31.

3 van Nies JAB, de Jong Z, van der Helm-van Mil AHM, et al. Improved treatment strategies reduce the increased mortality risk in early RA patients. Rheumatology 2010:49:2210-6.

4 Puolakka K, Kautiainen H, Pohjolainen T, et al. No increased mortality in incident cases of rheumatoid arthritis during the new millennium. Ann Rheum Dis 2010;69:2057-8.

5 Lindqvist E, Eberhardt K. Mortality in rheumatoid arthritis patients with disease onset in the 1980s. Ann Rheum Dis 1999;58:11-14.

6 Holmqvist M, Ljung L, Askling J. Mortality following new-onset rheumatoid arthritis: has modern rheumatology had an impact? Ann Rheum Dis 2018;77:85-91.

7 Gwinnutt JM, Symmons DPM, MacGregor AJ, et al. Twenty-year outcome and association between early treatment and mortality and disability in an inception cohort of patients with rheumatoid arthritis: results from the norfolk arthritis register. Arthritis Rheumatol 2017;69:1566-75.

8 Abhishek A, Nakafero G, Kuo C-F, et al. Rheumatoid arthritis and excess mortality: down but not out. A primary care cohort study using data from clinical Practice Research Datalink. Rheumatology 2018:57:977-81. 